\title{
A empregabilidade das pessoas com deficiência: uma análise da inclusão social no mercado de trabalho do município de Bauru, $\mathbf{S P}^{1}$
}

\author{
Rômulo Rodrigues Violante ${ }^{2}$ e Lúcia Pereira Leite ${ }^{3}$ \\ Departamento de Psicologia da Faculdade de Ciências da \\ Universidade Estadual Paulista, Campus de Bauru
}

\begin{abstract}
Amparada nos preceitos da inclusão social, esta pesquisa objetivou examinar a empregabilidade das pessoas com deficiência (PCD) em atendimento ao Decreto 3.298, que estabelece cotas para contratação de PCD para empresas com 100 ou mais funcionários. Foram entrevistados funcionários do setor de recursos humanos de 12 empresas de médio e grande porte de um município do oeste paulista, à luz de um roteiro estruturado. As entrevistas foram integralmente transcritas, categorizadas pelo critério da análise de conteúdo. Os resultados apontam que um terço das empresas privadas cumpre a regulamentação. As políticas empresariais priorizam contratações de pessoas cujas deficiências não exijam modificações estruturais no ambiente de trabalho, ou que então represente aspecto favorável à produção. A maioria dos entrevistados concebe a deficiência como um fenômeno de caráter individual. Embora tenham discursado sobre direitos iguais a todas as pessoas, grande parte ainda não apresenta discurso condizente com os pressupostos inclusivos, pois deixa de realizar ações de suporte para atender essa demanda populacional, esperando que o próprio indivíduo se ajuste às condições postas.
\end{abstract}

Palavras-chave: Pessoa com deficiência, Mercado de trabalho, Inclusão social.

Employment of people with disability: an analysis of social inclusion in the job market in the city of Bauru, SP

Based on the precepts of social inclusion, this research objected to examine the employment of people with disability (PWD), according to decree $\mathrm{n}^{\mathrm{o}} 3.298$ which establishes hiring quotas for PWD in companies with 100 or more employees. Interviews were made with employees of HR departments in 12 different companies located in the west side of the state of São Paulo, based on a structured script. All the interviews were transcripted and gathered in analysis categories. The results showed that one third of private companies comply with the regulation for employment of PWD. Corporate policies prioritize hiring of people whose disabilities do not demand structural modifications in the work environment, or those whose disabilities represent a positive aspect for production lines. The majority of the interviewed understand disabilities as an individual phenomenon. Although they have talked about equal rights for everyone, the majority of them do not present a consistent speech based on the precepts of social inclusion, for they fail to promote actions for supporting the population with disabilities and expecting that those with disabilities are the ones responsible to adjust themselves to all imposed conditions.

Keywords: Person with disability, Job market, Social inclusion.

\section{Introdução}

$\mathrm{O}$ debate sobre a inclusão social das pessoas com deficiência (PCD) no mercado de trabalho acompanha um movimento crescente de discussão que no Brasil já é amparada pela constituição de 1988, que assegura direito de igualdade a essas pessoas. Tem-se notado que tais discussões vêm ganhando cada vez mais espaço tanto no meio acadêmico como no midiático, suscitando assim o interesse por estudos voltados a analisar a temática.

1 Trabalho de iniciação científica financiado pela Fundação de Amparo à Pesquisa do Estado de São Paulo, FAPESP.

2 Psicólogo com atuação na área organizacional, graduado pela Faculdade de Ciências da Universidade Estadual Paulista (Unesp), campus de Bauru.

3 Psicóloga e Doutora em Educação. Docente do Departamento de Psicologia e do Programa de Pós-graduação em Psicologia do Desenvolvimento e Aprendizagem da Faculdade de Ciências da Universidade Estadual Paulista (Unesp), campus de Bauru. 
Numa alusão às normas prescritivas, no cenário brasileiro, têm-se a Constituição Federal de 1988 e o Decreto n⿳o 3.298 de 20/12/1999 - dispondo sobre a reserva de vagas no mercado de trabalho para pessoas com deficiência ,- que podem ser compreendidos como principais dispositivos legais que asseguram o direito de acesso ao mercado de trabalho às pessoas com deficiência. A Carta Magna garante a todo cidadão brasileiro seu direito à liberdade, acesso à educação, à saúde, ao lazer, ao trabalho (arts. 6 e 227) e, no que se refere ao campo do trabalho, proíbe qualquer tipo de discriminação por critérios de admissão ou salários do trabalhador com deficiência (art. 7); garante a promoção de assistência social, bem como adaptação de logradouros, de edifícios públicos e de transporte coletivo (art. 244).

Já o artigo 36, do Decreto n⿳o. 3.298, regulamenta a obrigatoriedade de empresas privadas, com 100 ou mais funcionários contratados, reservarem cotas entre $2 \%$ e $5 \%$ de suas vagas para pessoas que apresentem algum tipo de deficiência. $O$ referido decreto estabelece que empresas com até 200 funcionários devem ter $2 \%$ do quadro de empregados ocupados por PCD; entre 201 e 500, 3\%; entre 501 e 1.000, 4\%; e acima de $1.001,5 \%$, respectivamente (Brasil, 1999).

O mesmo documento, em seu artigo 37, dispõe sobre a reserva de $5 \%$ das vagas em concursos público para as PCD, assegurando o direito de se inscreverem em iguais condições dos demais candidatos, atendendo para tal a promoção de adaptações físicas requeridas pelos candidatos com deficiência (Brasil, 1999).

Embora a Secretaria de Fiscalização do Trabalho, do Ministério do Trabalho e do Emprego, apresente dados positivos sobre a inserção social de PCD nas empresas - em 2005 havia 12.786 funcionários com deficiência empregados e em 2007 esse número subiu para 27 mil funcionários (Revista "Psicologia Ciência e Profissão" - Diálogos, 2007), estudos recentes revelam que o número de $\mathrm{PCD}$ incluídas no mercado de trabalho ainda é bastante incipiente (Araújo \& Schmidt, 2006; Tanaka \& Manzini, 2005).

Dados do Censo Demográfico de 2000, realizado pelo IBGE, demonstram que, no quesito "mercado de trabalho", dos 66,6 milhões de pessoas de 10 anos ou mais de idade (faixa etária considerada em idade ativa) que compõem a população ocupada no País, nove milhões são pessoas com alguma deficiência. A taxa de empregabilidade para homens em idade ativa, com algum tipo de deficiência, é de 51,8\%, enquanto para homens em idade ativa sem nenhum tipo de deficiência a taxa é de $63 \%$, ou seja, uma diferença maior que $10 \%$. Diferença semelhante é observada entre as mulheres: a proporção de ocupadas varia entre $27,3 \%$ para mulheres com alguma deficiência e 37,2\% para mulheres sem nenhuma deficiência (IBGE/Censo, 2000).

Recorda-se que atualmente se fazem várias leituras críticas sobre o conceito de empregabilidade; entretanto, este texto se limita a reportar as ideias de Hirata (1997, citado por Teixeira, 2003), que aponta que a tendência mercadológica é exigir que os indivíduos cada vez mais procurem se desenvolver e, consequentemente, apresentar habilidades cognitivas, comunicativas e reflexivas. Nas palavras de Teixeira (2003):

[...] tais habilidades se traduzem em competências, compreendidas como uma capacidade do tipo particular, adquirida mediante o esforço pessoal. No entanto, a redução da oferta de trabalho e também das possibilidades de exercer a "empregabilidade", devido às crises das condições de produção capitalista, contribui para agravar as tendências de exclusão social dos menos aptos (Teixeira, 2003, pp. 7-8).

Numa alusão às PCD, percebe-se que, para esse segmento populacional, as dificuldades de empregabilidade tomam maior proporção, devido aos déficits orgânicos ou a concepções de incapacidade associadas à condição de deficiente. 
Em pesquisa realizada por Araújo e Schmidt (2006), da qual participaram 30 empresas de diferentes ramos de atuação na cidade de Curitiba, PR, constatou-se que apenas quatro empresas ( $13 \%$ da amostra) cumpriam a lei de cotas para contratação de PCD. Percebe-se então que poucas empresas incluem no seu quadro de funcionários pessoas com deficiência, na medida sugerida pela regulamentação legal.

Entretanto, uma sociedade inclusiva deve propiciar condições de trabalho para todos os sujeitos dela pertencentes, não admitindo preconceitos, discriminações, barreiras sociais, culturais ou pessoais, de modo que a inclusão de PCD deve inicialmente reconhecer as necessidades individuais próprias da condição de cada indivíduo e, então, possibilitar o acesso a todas as instâncias do desenvolvimento social (Bahia, 2006).

Ao definir "empresa inclusiva", Sassaki (1997) propõe como sendo aquela que contempla as diferenças individuais, acredita no valor da diversidade humana e promove mudanças internas, tanto físicas como administrativas, garantindo aos funcionários com deficiência a possibilidade de exercerem sua função com qualidade e autonomia. Sendo assim, para o autor a empresa inclusiva deve promover: a) adaptação dos locais de trabalho; b) adoção de esquemas flexíveis no horário de trabalho; c) revisão das políticas de contratação de pessoal; d) revisão dos programas de treinamento e desenvolvimento de recursos humanos; e) palestras que desmistifiquem a deficiência como incapacitante, dentre outras condições.

Há de se considerar que, embora o amparo legal existente no Brasil para contratação de PCD seja considerado avançado em relação ao de muitos países, as leis vigentes garantem apenas a obrigatoriedade da contratação, sem, entretanto, prover reais condições para que a inclusão social de PCD seja efetivamente realizada (Bahia, 2006).

No que tange ao aspecto educacional, a taxa de alfabetização das pessoas de 15 anos ou mais de idade era de $87,1 \%$ no Brasil. Já entre as pessoas com deficiência era de $72,0 \%$. Entretanto, do total de indivíduos com 15 anos de idade, ou mais, sem instrução ou com até três anos de estudo, 32,9\% tinham alguma deficiência (IBGE/Censo, 2000). Enquanto no grupo com menor instrução quase uma entre três pessoas era portadora de deficiência, entre os que concluíram pelo menos o primeiro grau, somente uma em cada dez pessoas possuía alguma incapacidade.

Em adicional à dificuldade de progresso educacional, há também as condições desfavoráveis de trabalho. Batista (2003, citado por Miranda, 2006) afirma que questões relacionadas à segurança dentro do ambiente de trabalho e a desinformação sobre as reais capacidades das PCD por parte dos empregadores influenciam as empresas a resistir em empregar tais indivíduos, e não somente a falta de qualificação profissional dessa demanda populacional.

Então, observa-se que as leis em benefício das PCD preveem atacar, principalmente, as consequências do processo de exclusão social. Tal processo está geralmente relacionado à dificuldade de acesso à educação regular e profissional, baixa renda e saúde pública deficitária, assim como a dificuldade da relação do indivíduo com deficiência e seu contexto social (Neri, 2003; Pastore, 2002).

Desconstruir a imagem do indivíduo deficiente como incapaz, improdutivo, lento, desprovido de qualidades e oneroso, e criar o conceito de um indivíduo capaz, produtivo, dotado de qualificação profissional é um trabalho árduo e lento, que deve ser compreendido como um compromisso social de diversas áreas, quando se pensa em promover condições mais igualitárias para o desenvolvimento humano e consequentemente criar condições para que o contexto o qualifique, favorecendo o estabelecimento de interações sociais entre pares não análogos, a saber: pessoas com e sem deficiência. 
Logo, o compromisso das empresas em promover a diversidade, respeitar as diferenças individuais e trabalhar no sentido de reduzir as desigualdades sociais deve ser compreendido por todos o sempresários, inclusive aqueles que não se sentem responsáveis pelo processo de inclusão social das PCD (Instituto Ethos, 2002).

Com base no exposto, o objetivo deste trabalho foi levantar, junto às empresas com 100 ou mais funcionários na cidade de Bauru, quais são as razões por que os empregadores contratam tais funcionários e identificar as concepções dos empregadores sobre: a pessoa com deficiência; o trabalho da pessoa com deficiência; inclusão social; e condições de trabalho ofertadas a essa demanda populacional.

\section{Método}

\section{Participantes}

Participaram desta pesquisa funcionários do setor de recursos humanos, responsáveis pelo recrutamento e seleção de 12 empresas da cidade de Bauru, SP, de diferentes ramos de atividade. Dessa amostra, dez advinham da iniciativa privada e duas de caráter público, todas com mais de 100 funcionários contratados.

\section{Instrumentos}

Foi utilizado um roteiro de entrevista semiestruturado, contendo 13 questões divididas em blocos temáticos, a saber: bloco 1: concepções sobre deficiência e inclusão social; bloco 2: políticas da empresa para contratação de PCD; e bloco 3: avaliação sobre o trabalho das PCD e condições de trabalho ofertadas a essa demanda populacional.

\section{Procedimentos}

Após aprovação da pesquisa pelo comitê de ética da Faculdade de Ciências da Unesp de Bauru (processo $\mathrm{n}^{\mathrm{o}}$ 1477/46/01/08), todas as empresas participantes foram inicialmente contatadas via correspondência.

As empresas que fizeram parte deste estudo foram selecionadas aleatoriamente a partir de uma listagem fornecida pelo Ministério do Trabalho e do Emprego de Bauru, que continha o cadastro de 101 empresas com 100 ou mais funcionários no município. Diante dessa amostra, 33 empresas (representando um terço do total) foram convidadas a participar da pesquisa por meio de carta convite enviada pelos correios, porém, mesmo após sucessivas solicitações, apenas 12 responderam positivamente.

As entrevistas foram realizadas pessoalmente nas dependências das empresas, a partir de data e horário previamente agendados por telefone, e gravadas para posterior transcrição.

Para a análise dos dados qualitativos, as entrevistas foram transcritas em sua íntegra e os dados foram aglutinados em categorias de análise - concepções sobre PCD, concepções sobre o trabalho das PCD, razões para contratação e critérios de admissão -, cujos conteúdos elucidaram as questões norteadoras no roteiro de entrevista previamente formulado. 


\section{Resultados}

\section{Caracterização das Empresas}

As 12 empresas participantes da pesquisa pertencem a diversos ramos de atividade, sendo majoritariamente da iniciativa privada $(83,3 \%)$, e possuíam em seu quadro funcional entre 107 e 4.010 funcionários, conforme o Quadro 1.

\section{Quadro 1: Caracterização geral das empresas participantes}

\begin{tabular}{|l|l|l|l|l|l|}
\hline Ramo de atividade & Setor & $\begin{array}{l}\text { № de } \\
\text { funcionários }\end{array}$ & $\begin{array}{l}\text { № de PCD } \\
\text { contratadas }\end{array}$ & $\begin{array}{l}\text { № de contratações } \\
\text { exigidas pela Lei }\end{array}$ & $\begin{array}{l}\text { Relação entre as contratações } \\
\text { efetivadas e as exigidas }\end{array}$ \\
\hline Construtora* & Público & 107 & 3 & - - & -- \\
\hline Indústria & Privado & 200 & 5 & 4 & +1 \\
\hline Indústria & Privado & 201 & 5 & 6 & -1 \\
\hline Indústria & Privado & 320 & 10 & 9 & +1 \\
\hline Prest. Serviços* & Público & 402 & 65 & - & - \\
\hline Indústria & Privado & 440 & 18 & 13 & +5 \\
\hline Prest. Serviços & Privado & 451 & 4 & 13 & -9 \\
\hline Prest. Serviços & Privado & 684 & 13 & 27 & -14 \\
\hline Frigorífico & Privado & 856 & 7 & 34 & -27 \\
\hline Prest. Serviços & Privado & 1.350 & 21 & 67 & -46 \\
\hline Prest. Serviços & Privado & 1.854 & 9 & 92 & -83 \\
\hline Prest. Serviços & Privado & 4.010 & 35 & 200 & -165 \\
\hline * Empresas públicas. & & & & & \\
\hline
\end{tabular}

Pode-se observar que, das dez empresas privadas, apenas três (30\% da amostra) cumprem a lei de cotas para contratação de PCD. Nota-se que, quanto maior o número de funcionários, maior é o déficit de funcionários com deficiência que deveriam ser contratados pela empresa.

No que se refere às empresas públicas entrevistadas, verificou-se que, embora não sejam obrigadas, por lei, a contratar um determinado número de PCD, e sim reservar até $20 \%$ das vagas dos concursos públicos para essa população - conforme Lei 8.112/90 -, tais empresas incluem PCD em seu quadro de funcionários. Isso pode ser notado principalmente na de Prestação de Serviços (de competência federal), que tem parceria com uma fundação para contratação dos funcionários com deficiência, porém esses deixam de se caracterizar como funcionários contratados por meio de concurso público dessa empresa, não tendo os mesmos benefícios trabalhistas dos demais (salário semelhante, programa de capacitação profissional, plano de carreira, entre outros).

Nas 12 empresas entrevistadas o total de funcionários chega a 10.875, dos quais 195 funcionários apresentam alguma deficiência, ou seja, 1,8\% do total. Ressalta-se que desse total incluem-se duas empresas de caráter público, às quais não se aplica a lei de cotas, conforme mencionado.

Assim, pensou-se em dividir a amostragem de empresas do setor privado, para retratar melhor a realidade investigada neste estudo. O Quadro 2 procura demonstrar tal dado: 
Quadro 2: Caracterização das empresas privadas

\begin{tabular}{|l|l|l|l|l|l|}
\hline Ramo de Atividade & № de funcionários & $\begin{array}{l}\text { № de PCD } \\
\text { contratadas - } \\
\text { FA(n) }\end{array}$ & FR (\%) & $\begin{array}{l}\text { № de } \\
\text { contratações } \\
\text { exigidas pela lei }\end{array}$ & $\begin{array}{l}\text { Percentual de } \\
\text { contrataçoses de } \\
\text { PCD exigido pela lei } \\
\text { (\%) }\end{array}$ \\
\hline Indústria & 200 & 5 & 2,5 & 4 & 2 \\
\hline Indústria & 201 & 5 & 2,5 & 6 & 3 \\
\hline Indústria & 320 & 10 & 3,1 & 9 & 3 \\
\hline Indústria & 440 & 18 & 4 & 13 & 3 \\
\hline Prest. Serviços & 451 & 4 & 0,9 & 13 & 3 \\
\hline Prest. Serviços & 684 & 13 & 1,9 & 27 & 4 \\
\hline Frigorífico & 856 & 7 & 0,8 & 34 & 4 \\
\hline Prest. Serviços & 1.350 & 21 & 1,6 & 67 & 5 \\
\hline Prest. Serviços & 1.854 & 9 & 0,5 & 92 & 5 \\
\hline Prest. Serviços & 4.010 & 35 & 0,8 & 200 & 5 \\
\hline Total & 10.366 & 127 & 1,2 & 465 & $4,4^{*}$ \\
\hline * Média ponderada dos percentuais segundo lei de cotas, de acordo com número de funcionários. & \\
\hline
\end{tabular}

$\mathrm{Na}$ análise do Quadro 2, nota-se que as contratações de PCD pelas empresas privadas ainda está aquém da exigência da Lei de Cotas. No total de 10.366 funcionários contratados pelas dez empresas privadas entrevistadas, apenas 127 (1,2\%) são funcionários com alguma deficiência, quando esse número, de acordo com tal regulamentação, deveria ser de 465 $(4,4 \%)$.

Apenas três empresas privadas (30\%) da amostra cumprem o percentual para contratação de PCD estabelecido pela lei. Ressalta-se que duas delas relataram contratar apenas funcionários com deficiência auditiva leve, isto é, que não tenham comprometimento grave na comunicação. Entretanto, os funcionários com deficiência auditiva de uma dessas empresas são, na verdade, funcionários acidentados no próprio ambiente de trabalho e que, após a perda parcial da audição, foram incluídos no quadro de funcionários com deficiência.

\section{Análise de discurso}

\section{Concepções sobre PCD}

Antes de iniciar a apresentação das concepções dos entrevistados acerca das PCD, fazse importante explicitar o conceito de deficiência no qual este trabalho se debruça, haja vista que o próprio entendimento do que é deficiência não tem sido objeto de consenso.

Historicamente, a deficiência está associada a uma situação de desvantagem. Refere-se à condição de uma situação de desequilíbrio que só é possível num esquema comparativo: aquela pessoa, com alguma deficiência, em relação aos demais membros do seu grupo, ou seja, a ideia de desvantagem só se faz pertinente quando se considera e julga determinado indivíduo em relação aos outros dentro de um grupo específico. Amaralian et al (2000) definem desvantagem como:

[...] prejuízo para o indivíduo, resultante de uma deficiência ou uma incapacidade, que 
limita ou impede o desempenho de papéis de acordo com a idade, sexo, fatores sociais e culturais. Caracteriza-se por uma discordância entre a capacidade individual de realização e as expectativas do indivíduo ou do seu grupo social. Representa a socialização da deficiência e relaciona-se às dificuldades nas habilidades de sobrevivência (Amarilian et al., 2000, p. 98).

Em outros termos, a desvantagem deriva da condição de deficiência, apresentada pelo indivíduo que a possui, que carrega consigo o status de incapacidade - gerada por essa mesma condição em função de o ambiente não se apresentar adaptado para promover a inserção total da PCD nas instâncias sociais. Com isso, esse segmento populacional se apresenta em situação de prejuízo perante o grupo de pessoas sem deficiências ao acessar ou tentar usufruir das oportunidades sociais.

Para além de tais prejuízos a PCD é ainda estigmatizada por pares deficientes ou não. Ao fazer uma análise das considerações de Goffman (1988) apresentadas na célebre obra Estigma: notas sobre a manipulação da identidade deteriorada, constata-se que estigma é um termo de origem grega que indicava sinais corporais, e a pessoa que o possuía era ritualmente poluída e deveria ser evitada. $\mathrm{Na}$ era cristã, os estigmas eram vistos de duas formas: alusão religiosa (sinais que aparecem no corpo para indicar graça divina) ou alusão médica (sinais que aparecem no corpo para indicar algum tipo de distúrbio físico). Conceito usual: um atributo depreciativo, fraqueza, desvantagem. $\mathrm{Na}$ atualidade a pessoa é estigmatizada por possuir característica (física, intelectual, social, econômica, cultural etc.) diferente da aceita pela sociedade.

Basicamente o estigma pode ser determinado devido a dois fatores: identidade social virtual, considerada por aquilo que se espera - projeção imaginativa; identidade social real, categorias e atributos que o indivíduo realmente possui. É através da comparação feita pela sociedade ou pelo próprio individuo estigmatizado entre essas duas identidades que o estigma irá se criar e fortificar. Assim, sujeitos caracteristicamente distintos de pessoas comuns são estigmatizados com um profundo sentido depreciativo, sinalizando-o como um sujeito inferior, marcado negativamente no contexto social (Goffman, 1988).

No contraponto ao amparo legal a respeito, nas disposições do Decreto 3.298, de 20 de dezembro de 1999, que dispõe sobre a política nacional para integração da PCD, essa é considerada como:

[...] toda perda ou anormalidade de uma estrutura ou função psicológica, fisiológica ou anatômica que gere incapacidade para o desempenho de atividade, dentro do padrão considerado normal para o ser humano (art. $3^{\circ}, \S 1^{\circ}$ ).

Essa definição, notoriamente, foca no indivíduo com deficiência toda a responsabilidade pela origem de sua condição, já que não faz a leitura do contexto social no qual a pessoa está inserida, sendo um conceito estritamente médico-jurídico, estigmatizando assim a pessoa que a possui. Além disso, o próprio conceito de "normal" pode ser questionado: qual o parâmetro para se considerar alguém anormal? Por que uma pessoa com deficiência deve ser considerada anormal? (Figueiró, 2007).

Ao dissertar sobre essas questões, Amaral (1998) destaca que a diferença surge no contexto das normalizações, daquilo que se pretende homogeneizador, semelhante, no contexto apegado às normas de correspondência a um modelo estabelecido. Aponta que em nossa sociedade o padrão ideal de normalidade corresponde ao sujeito "jovem, do gênero masculino, branco, cristão, heterossexual, física e mentalmente perfeito, belo e produtivo" (Amaral, 1998, p. 14). Esses padrões físicos e comportamentais presentes e valorizados nas relações sociais ocidentais acabam por definir como diferente, desviante ou anormal todo aquele que não se enquadra em seus termos, e quão mais distante desses o indivíduo está, mais 
desviante será. A caracterização da diferença vem, geralmente, acompanhada do estigma, sob o qual se submetem as relações que envolvem esse sujeito e o outro.

Os preceitos apresentados pretendem contrapor a concepção de deficiência trazida pelo Decreto 3.298; assim, esta pesquisa tomará como referência, para análise de seus dados, o ideário proposto por Omote (1996):

[...] a definição de deficiência perde o caráter oficial e universal. Passa a ser contingencial. As pessoas começam a compreender que alguém é deficiente somente em um contexto temporal, espacial e socialmente determinado. Começam a compreender que é necessário especificar os critérios segundo os quais ele é deficiente (Omote, 1996, p. 130).

Além dos acometimentos orgânicos, a deficiência pode ser entendida como uma condição social caracterizada pela limitação ou impedimento da participação da pessoa deficiente nas diferentes instâncias do debate de ideias e de tomada de decisões na sociedade (Aranha, 2003; Omote, 1996).

Este estudo se ampara na compreensão do fenômeno da deficiência, que deve contemplar o contexto histórico, as crenças e suposições daqueles que reconhecem e tratam distintivamente uma PCD, sendo insuficientes as análises que focalizam a condição de deficiência somente no indivíduo. Em outras palavras, o perigo reside quando só é notada a incapacidade pessoal sem considerar razões sociais que levam ou enfatizam tal condição (Omote, 1987).

O Quadro 3 procura ilustrar os dados obtidos a partir da análise das falas dos participantes:

Quadro 3: Frequência da ocorrência da categoria concepção sobre pessoa com deficiência dos empregadores

\begin{tabular}{|l|l|l|}
\hline Subcategorias & FA (n) & FR (\%) \\
\hline Limitação exclusivamente pessoal e ideia de falta na pessoa com deficiência & 6 & 50 \\
\hline Limitação pessoal, porém contextualizada (limitação para determinadas atividades) & 4 & 33,3 \\
\hline Pessoas que necessitam de atendimento diferenciado & 2 & 16,7 \\
\hline Totais & 12 & 100
\end{tabular}

Em um cotejo dos dados encontrados percebe-se que as concepções dos entrevistados aproximam-se mais daquela disposta pelo Decreto 3.298 do que da que faz menção à desvantagem como produto no social, ou seja, de como a falta de ajustes sociais pode dificultar a participação da PCD, uma vez que a sociedade não se mobiliza para promover as adequações necessárias para o atendimento às especificidades desse segmento populacional (Aranha, 2003; Omote, 1996).

Entretanto, foi possível observar uma diferenciação entre os entrevistados que concebem a deficiência como uma limitação ou falta exclusivamente do indivíduo e aqueles que buscam uma melhor contextualização para explicar a deficiência, isto é, buscam no ambiente um agravante para uma condição de desviante do deficiente, afastando-se do normal.

Na subcategoria limitação exclusivamente pessoal e ideia de falta na pessoa com deficiência, foram identificadas concepções que atribuem às PCD todo o encargo de suas limitações; cinquenta por cento dos entrevistados, indicados como P, estão nessa subcategoria. A seguir encontram-se alguns exemplos de concepções sob esse paradigma: 
[...] uma deficiência de alguma coisa a mais pra ela poder aprender, por exemplo... Alguma deficiência que ela pode suprir. [...] uma falta de alguma coisa, que possa impedir a pessoa de realizar algo (P7).

Ah... é uma pessoa que tem alguma limitação em relação ao conviver socialmente, alguma coisa que impeça ela de caminhar normalmente. Mas não que isso seja um efeito de demérito, sabe... Quando a gente fala de deficiente, o único defeito que eu percebo é esse. [...] algum aspecto dessa pessoa é reduzido em relação aos demais. Ela tem alguma... alguma... alguma... limitação (P8).

As falas reproduzidas indicam concepções antagônicas daquela proposta por Omote (2001), quando o autor sugere que se pense a deficiência como um fenômeno social, isto é, o meio social é quem irá determinar se a perda ou alteração de uma dada pessoa seria deficiência ou não, uma vez que a audiência é a responsável por dizer se o prejuízo apresentado é relevante ou não para a integridade moral e social da pessoa. A audiência, nessa situação, pode ser entendida como os diversos segmentos da comunidade e seus respectivos agentes (agências que estabelecem políticas públicas; agências de formação - escola, universidades, etc.; agências de comunicação - mídia e propaganda; e outras agências de grupos específicos - representantes de categorias, por exemplo) que em alguma medida estão envolvidos direta ou indiretamente com a deficiência, atribuindo maior ou menor condição de capacidade às pessoas alocadas nessa condição, ou seja, as pessoas sem deficiência é que acabam, na maioria das vezes, por julgar e decidir as competências das pessoas com deficiência projetando o que podem ou não executar.

Ainda, dentre os $50 \%$ que consideram a deficiência um fenômeno exclusivamente individual, dois relatos trazem a dicotomia normalidade versus anormalidade.

Eu acho que é alguma limitação, a pessoa tem alguma limitação [...] mas a gente vê que é normal, normal... O J. até joga bola! Ele tem o sorriso lindo e você pensa: "meu Deus do céu, ele é feliz!" (P6).

A deficiência é alguma questão assim... que faltou... faltou algo... Mas não que impeça ela de ser um ser humano total. Eles participam dos jogos de futebol, do churrasco da empresa. Para eles, é tudo normal, participam de tudo (P9).

Percebe-se, a partir desses relatos, que há uma subestimação das reais capacidades das PCD, de modo que aqueles cujas deficiências não os impeçam de praticar atividades físicas, ou frequentar ambientes sociais, sofrem com o estigma de terem algum tipo de limitação. Fica evidente que tais entrevistados enxergam a pessoa com deficiência pelo prisma das marcas, e não pelo seu valor ou mérito.

Vê-se que, para um dos entrevistados, a felicidade está diretamente vinculada à possibilidade de ser normal, como se um indivíduo com deficiência, em função do seu prejulgamento de anormal, não pudesse ser feliz, ou demonstrar tal emoção. O relato de P6 mostra como os padrões subjetivos ainda se embasam numa ideia de que deficiência não combina com sentimentos positivos e é entendida como algo negativo, através de uma conotação assistencialista por quem a julga, em que os sentimentos de comoção social combinam mais do que os considerados "normais" de felicidade.

Consideravelmente diferenciados, outros 33,3\% dos relatos de quatro participantes enquadraram-se na subcategoria limitação pessoal, porém contextualizada (limitação para determinadas atividades). A seguir, algumas falas que ilustram tais concepções.

Eu entendo que a pessoa com deficiência... ela apenas tem uma limitação, mas isso nós temos também. Se você me colocar em um banco, dentro de uma instituição financeira, eu vou ter dificuldade porque não lido bem com números... Então eu enxergo como uma limitação para alguma coisa, mas que não torna a pessoa incapaz para o trabalho (P2). 
[...] são as pessoas que, devido à deficiência delas, têm uma restrição para algumas atividades [...] Uma pessoa com deficiência auditiva, a gente entende que, por ela ter uma deficiência auditiva, ela nunca poderá ser, por exemplo, telefonista, devido à própria deficiência (P5).

As falas reproduzidas revelam que, apesar da tentativa dos entrevistados de contextualizar a deficiência como visível em determinados ambientes de trabalho, na execução de determinadas atividades, ainda concebem a PCD como limitada, sendo incapaz de realizar determinadas atividades, não alertando para as possibilidades de adequações do espaço, para minimizar as limitações da deficiência.

Tais considerações são compartilhadas com os achados de Tanaka e Manzini (2005), ao relatarem que os empregadores incorrem no risco de enquadrar a especificidade da deficiência ao tipo de função, ao invés de tentar adaptar a função à pessoa por meio da utilização de recursos adaptativos e auxiliares. Para os autores, ao se escolher um trabalho somente em função da limitação da pessoa, corre-se o risco de rechaçar suas reais necessidades e também sua possibilidade e capacidade para o trabalho.

Esse fato pode ser elucidado a partir da seguinte fala:

[...] quando contratamos o E., o encarregado dele veio conversar com o médico e o médico perguntou: "para a função que ele vai exercer, a limitação vai atrapalhar?". Daí, o encarregado disse que não e o médico respondeu: "então não tem problema, pode contratar!" (P6).

Ainda $16,7 \%$ dos entrevistados apresentaram uma concepção de que condições ambientais e sociais pobres em recursos adaptativos e auxiliares podem representar fatores agravantes para a deficiência, necessitando, inclusive, de fatores diferenciadores durante um processo seletivo. Tais entrevistados compõem a subcategoria pessoas que necessitam de atendimento diferenciado.

É aquela pessoa que tem um certo grau de dificuldade em participar de um processo seletivo normal e concorrer com os demais. Precisa de uma atenção um pouco diferenciada, maior e tal... Não concorre de igual para igual com os demais, ok? (P3).

[...] eu entendo assim... é... até pelo estado emocional dessas PCD, elas precisam de um apoio maior, né? [...] Quando essas pessoas chegam até nós, precisando de uma oportunidade de trabalho, elas não vêm só pela procura do trabalho, mas elas trazem com elas todo um sentimento psicológico, um estado emocional, tudo que elas têm ali fora elas acabam refletindo aqui dentro. Então elas precisam de uma atenção diferenciada, né? (P12).

Apesar de terem enfatizado a necessidade de atenção diferenciada para as PCD, os referidos entrevistados focam as dificuldades nas PCD e não nas condições ambientais, já que concebem o ambiente como possível dificultador e não como sendo a variável crítica no estudo da deficiência, como propõe Omote (2001).

A maioria dos relatos traz a reflexão de como a deficiência ainda está fortemente ligada à ideia de incapacidade, em que a PCD é responsável pela sua condição, apresentando uma visão estigmatizante, o que para Figueiró (2007) incorre no sério risco de isentar a sociedade da responsabilidade sobre a origem e o agravamento da deficiência. 


\section{Concepções sobre inclusão social}

Para proceder à análise das respostas sobre inclusão social, partiu-se do pressuposto de que a sociedade como um todo deve se adaptar para incluir todas as demandas populacionais que se encontram excluídas socialmente, fugindo de uma perspectiva cotidiana que ainda entende que o indivíduo deve se adaptar à sociedade.

Assim, o tema "inclusão social" será tratado como responsabilidade de uma sociedade em prover condições estruturais, sociais e econômicas para que todos os sujeitos exerçam seus direitos e obrigações de cidadãos, de modo que essa mesma sociedade deva prover os ajustes necessários no suprimento às demandas de todo e qualquer indivíduo (Sassaki, 2003).

Neste debate, discute-se sobre a equidade de direitos, com referência às oportunidades de inclusão das PCD no mercado de trabalho. $\mathrm{O}$ discurso de equidade faz referência à garantia de oportunidades iguais às pessoas diferentes, para que todos possam ter os mesmos direitos. Em virtude dessa premissa os ajustes e/ou adaptações hão de ser feitos para que essas pessoas, como quaisquer outras, tenham oportunidades iguais no usufruto das regulamentações previstas na Constituição Federal de 1988, dentre elas as oportunidades de trabalho. Nesse sentido, muito embora o artigo 5o da Constituição mencione que todos são iguais perante a lei, ela própria estipula algumas regras diferenciadoras, protetivas e integradoras, em benefício das pessoas com deficiência, pois esse foi um dos valores substantivos estabelecidos no ordenamento jurídico constitucional. Resumindo, o princípio da igualdade consiste em dar tratamento igualitário aos iguais e tratamento diferenciado aos diferentes. Por essa razão é que se admite tratamento diferenciado para a mulher, se comparada aos homens, para a criança e o idoso se comparados ao adulto e à pessoa com deficiência se comparada a uma pessoa que não apresente qualquer tipo de deficiência (Napolitano, 2003).

Omote (1999) defende que uma sociedade inclusiva deve oferecer uma ampla gama de serviços especializados para atender todas as especificidades dos indivíduos com deficiências, pois somente assim poder-se-ão reduzir as desigualdades de oportunidades decorrentes das condições adversas que vivem algumas pessoas.

O Quadro 4 procura demonstrar as subcategorias identificadas a partir das falas dos entrevistados sobre o tema "inclusão social":

\section{Quadro 4: Frequência da ocorrência da categoria concepção sobre inclusão social}

\begin{tabular}{|l|l|l|}
\hline Subcategorias & FA (n) & FR (\%) \\
\hline Oportunidades iguais - sem menção às necessidades de adequação do contexto & 7 & 58,3 \\
\hline Necessidade de adequações para a inclusão & 3 & 25 \\
\hline Não apresentaram definição & 2 & 16,7 \\
\hline Totais & 12 & 100 \\
\hline
\end{tabular}

A partir da categorização das falas dos entrevistados, pode-se constatar que 58,3\% dos entrevistados entendem a inclusão social como a necessidade de que todos os indivíduos de uma sociedade tenham oportunidades iguais, para trabalho, escolarização, acesso à saúde pública etc. Entretanto, não mencionam qual ou quais adequações sociais e/ou ambientais devem ser feitas para que realmente haja a inclusão social das PCD. Embora apresentem a ideia de que todos têm direitos e deveres, não expõem o papel da sociedade para a realização dessa premissa. Assim, suas falam compõem a subcategoria Oportunidades iguais - sem menção às necessidades de adequação contextual. Insere-se a seguir alguns exemplos de relatos que ilustram tais concepções: 
Inclusão social eu entendo que seria nada mais do que você pegar essas pessoas especiais e tentar incluir no meio das pessoas que não têm essa... essa... deficiência! Eu entendo dessa forma e também não vejo problema nenhum, não; como eu disse pra você, nós já tivemos esse grupo de pessoas aqui na empresa e aqui eles participam de todas as atividades sociais junto dos demais (P3).

Eu acho que é assim: é fazer parte! Vida normal, sabe... É normal! Não só pro lado da deficiência, mas tudo! Existem "n" fatores aí que a pessoa acaba se excluindo e você tem que resgatar [...] É fazer parte do todo... É pegar aquela pessoa que está fora e colocar novamente no contexto. Colocar novamente no seu dia a dia (P6).

As respostas dos entrevistados aproximam-se do conceito de integração social, tratado por Aranha (2003) como um processo pelo qual o sujeito com deficiência é auxiliado a adquirir as condições e padrões mais próximos o possível da vida cotidiana dos demais indivíduos, para que somente assim possa ser introduzido na sociedade.

O conceito de integração social traz consigo a ideologia de normalização das PCD, uma vez que o foco de adequação para integração é no sujeito com a deficiência, e não no contexto social no qual está inserido. Os indivíduos deveriam, então, ser "trabalhados" para que se aproximassem dos níveis de normalidade de uma dada sociedade, localizando no sujeito o alvo da mudança. Dito de outro modo, a sociedade dá oportunidade à pessoa com deficiência, porém se ampara na ideia de superação desta, não reconhecendo a diversidade humana, ou seja, que todas as pessoas são diferentes e, para usufruírem dos mesmos direitos, necessitam de respostas sociais e econômicas diferenciadas para o convívio comum.

Em uma perspectiva mais ampla no entendimento de inclusão social, pensa-se num processo de ajuste mútuo, em que indivíduo e sociedade se preparam para que todas as necessidades individuais sejam atendidas e condições sejam dadas para que as PCD possam galgar um status de maior igualdade com os demais. Logo, a inclusão deve prever intervenções decisivas tanto no processo de desenvolvimento das PCD como no processo de reajuste da realidade social (Aranha, 2003; Sassaki, 1997).

Mais próximos do conceito citado estão 25\% dos relatos dos entrevistados, compondo a subcategoria denominada necessidades de adequação social para inclusão. Eis alguns exemplos:

Eu acho que é trazê-los para conviver na sociedade igualmente aos outros, numa sociedade mais igualitária [...] Então é uma inclusão social mesmo, é trazê-los para dentro da sociedade, e a sociedade tem que aceitá-los. Eles não têm que se adaptar à sociedade, e sim a sociedade que tem que se adaptar a eles (P9).

É receber essas pessoas que têm essas limitações, é nos adaptarmos a elas! Eu penso que não temos que separar as pessoas entre deficientes e não deficientes, e é nessa perspectiva que eu trabalho aqui... de adaptação mesmo! (P10).

As concepções enquadradas nessa subcategoria apresentam um diferencial, uma vez que mencionam a necessidade de adequação do contexto para que ocorra a inclusão, tirando do sujeito com deficiência a responsabilidade de se adequar ao espaço.

Compondo a subcategoria de menor representatividade na conceituação de inclusão social, $16,7 \%$ dos entrevistados não conseguiram definir o conceito, tendo sido agrupados na subcategoria daqueles que não apresentaram definição. Como evidenciado no relato:

Então, inclusão social pra mim é um processo de uma empresa que... assim, está muito antenada com várias coisas que o mercado exige, entendeu? Então, assim, é algo muito novo que a gente não tem noção da extensão do termo. E não sei. Eu não vejo como algo que possa estar dissociado de qualquer empresa. Toda empresa tem que ter esse tipo de 
postura, toda empresa tem que estar atenta a esse tipo de necessidade [...] Uma sociedade não sabe o que é isso (P8).

\section{Concepções sobre o trabalho das PCD}

Em uma sociedade cujo modo de produção é baseado na lógica do capital, o trabalho se torna uma importante via para inclusão social dos indivíduos com deficiência, pois "o trabalho é visto essencialmente como possibilidade de inserção no circuito produção-consumo. Assim o indivíduo deve produzir e consumir para que possa ser visto como cidadão" (Amaral, 1992, p. 131).

O trabalho, entendido como uma atividade que leva à construção de algo, é uma atividade essencialmente social, de modo que aqueles indivíduos que têm o direito do trabalho garantido buscam, por meio dele, se inserir no espaço social, afirmando-se como indivíduo produtivo.

Portanto, entende-se que o trabalho não significa apenas exercer uma atividade produtiva, mas também conviver, sentir-se indivíduo e cidadão, cabendo à organização do trabalho preocupar-se inclusive com o mundo social do indivíduo, e não somente com o produtivo (Dejours, 1999).

A obra de Marx traz uma crítica com relação à alienação do trabalho no modo de produção capitalista. Para Marx (1993), o trabalho realizado pelo operário não pertence a sua natureza, mas é condição para que ests sobreviva minimamente, sendo obrigado a, muitas vezes, adequar-se às condições degradantes de trabalho. Por esse fato, o indivíduo apenas se esgota e não se realiza na plenitude de suas capacidades mentais e físicas. Nas palavras de Marx (1993, p. 80), o trabalho "não constitui a satisfação de uma necessidade, mas apenas um meio de satisfazer outras necessidades". Dessa forma, o trabalhador vende seu tempo, seu sentimento, sua força por uma quantia de dinheiro e, de posse deste, pode trocá-lo por condições de sobrevivência. Esse trabalho alienado é um processo de mortificação, em que o homem exerce uma atividade cansativa que não condiz com sua aspiração de indivíduo opinante, de cidadão livre.

Dejours (1999) também aponta para as contradições existentes nas relações de trabalho, pois trabalhar pode causar infelicidade e auto-realização ao mesmo tempo. Entretanto, afirma que a impossibilidade de realizar um trabalho é também fonte de sofrimento numa sociedade do capital.

O fato é que o trabalho é uma fonte inesgotável de paradoxos. Incontestavelmente, ele dá origem a terríveis processos de alienação, mas pode ser também um possante instrumento a serviço da emancipação, bem como do aprendizado e da experimentação, da solidariedade e da democracia (Dejours, 1999, p. 141).

Destarte, ainda que o trabalho, sob a ótica do modo de produção capitalista, possa ser entendido como alienado, é por meio dele que os indivíduos garantem o acesso às esferas sociais, ou seja, o trabalho possui a função de legitimar o cidadão como tal (Cotrim, 1996, citado por Silva, 2007).

O Quadro 5 apresenta as concepções trazidas pelos entrevistados: 
Quadro 5: Frequência da ocorrência da categoria concepção sobre trabalho da pessoa com deficiência

\begin{tabular}{|l|l|l|}
\hline Subcategorias & FA (n) & FR (\%) \\
\hline Premissa de que haveria problemas & 4 & 33,3 \\
\hline Desempenho igual dos empregados sem deficiência & 4 & 33,3 \\
\hline Deficiência como vantagens para o trabalho & 2 & 16,6 \\
\hline Trabalho avaliado independente da deficiência & 2 & 16,6 \\
\hline Totais & 12 & 100 \\
\hline
\end{tabular}

Para 33,3\% dos entrevistados que compõem a subcategoria premissa de que haveria problemas, o trabalho das PCD é visto como aquele que, primariamente, poderia causar algum problema no ambiente de trabalho, porém acaba superando as expectativas dos empregadores, pois tais problemas não acontecem na realidade de trabalho em que estão inseridos.

A seguir exemplos que ilustram essa categoria.

Não dá problema! Não, não tem problema. Por exemplo, aquele deficiente físico, do braço, que eu te falei, ele não tem problema nenhum em relação ao que ele está desenvolvendo, mesmo sendo um trabalho operacional (P8).

Assim, é uma graça, sabe? Eu nunca tive problema com nenhum deficiente físico. Nunca! Por incrível que pareça! (P11).

A partir da análise dos discursos transcritos, vê-se que os entrevistados estigmatizam o sujeito com deficiência como sendo aquele que possivelmente causaria algum transtorno no ambiente de trabalho, dando-lhe todo o descrédito em decorrência de sua deficiência.

O estigma atido nos indivíduos com deficiência os torna sujeitos inferiores, cujas marcas da deficiência os sinalizam negativamente no contexto social e principalmente, nesse caso, no contexto do trabalho. A partir do estigma surge a "deficiência secundária", assim chamada por Amaral (1992), que extrapola a deficiência para além da diferença em si e atinge os níveis sociais a partir de uma leitura errônea do que seja a deficiência.

Portanto, aos indivíduos com deficiência é atribuído todo o descrédito que a leitura social desse fenômeno lhes confere, de modo que sua presença no ambiente de trabalho é, a priori, indesejada, haja vista que os discursos aqui transcritos revelam a surpresa com o fato de as PCD não causarem qualquer intercorrência no exercício da função.

Na opinião de outros 33,3\% dos participantes da pesquisa, o desempenho profissional dos funcionários com deficiência é avaliado como sendo de igual eficiência daqueles funcionários sem nenhum tipo de deficiência, ou seja, quando questionados sobre a visão que têm do trabalho desses funcionários, tais entrevistados partem de um único referencial, qual seja: o desempenho dos funcionários sem deficiência, explicitando a dicotomia existente entre trabalho das pessoas sem deficiência e trabalho das PCD.

Os relatos a seguir expressam opiniões dos participantes sobre o desempenho no trabalho, e todos eles avaliaram tal desempenho como sendo igual ao dos empregados sem deficiência.

O serviço que eles prestam é muito bom. [...] são simpáticos, fazem o serviço direitinho. Eu acho normal... normal mesmo. Igual ao de todo mundo (P7).

Normal, iguais aos outros. Até porque as atividades que eles estão executando, as limitações que eles têm não vão comprometer. E seria injusto... por isso que colocamos eles 
em atividades que eles consigam exercer como os outros colegas (P10).

Contrapondo-se aos relatos das categorias já discutidas, 16,6\% dos entrevistados consideram que as próprias deficiências podem representar vantagens para o exercício das funções atribuídas aos indivíduos com deficiências.

De todas as PCD contratadas, $42 \%$ são deficientes auditivos, o que, de acordo com os entrevistados P2 e P3, representa uma vantagem para a linha de produção, visto que aquelas com deficiência auditiva distraem-se menos durante a jornada. Seguem relatos que compõem a subcategoria deficiência como vantagem para o trabalho.

A maior briga é de que as pessoas não podem ficar falando na linha de produção, para evitarmos contaminação e tudo mais. Muitos usam máscaras, mas não são todos. Então, por exemplo, nossos deficientes auditivos acabam sendo importantes, pois eles não ficam conversando durante o trabalho. São pessoas que não ficam aqui criando tumulto na linha de produção, não conversam durante o horário de trabalho, então o foco no trabalho acaba sendo maior (P2).

Determinadas atividades que nós identificamos aqui na empresa, o portador de deficiência se sai tendo um desempenho melhor. Então, a gente enxerga o benefício que o deficiente pode trazer para nossa produção. A questão do surdo e mudo: ele está concentrado naquela atividade e qualquer barulho ali do lado não vai desviar a atenção dele. Então ele vai estar focado no que está fazendo e isso vai aumentar a eficiência na produção (P3).

Os entrevistados, cujas concepções se fundamentam nas supostas vantagens para a produção, ao contratarem funcionários com determinado tipo de deficiência, correm o risco de admitir pela deficiência e não pelas reais capacidades dos indivíduos (Tanaka \& Manzini, 2005), deixando de adaptar a função às condições das PCD.

Outros 16,6\% dos entrevistados enxergam o trabalho das PCD a partir do trabalho em si, ou seja, não partem de nenhum estigma vivido por essa demanda populacional. Representam, assim, os relatos mais condizentes com a proposta de compreender o trabalhador com deficiência como um indivíduo que, dadas as condições necessárias, pode exercer um trabalho com qualidade e eficiência.

O trabalho é realizado dentro da normalidade. [...] não existe reclamação de qualidade nem produtividade do trabalho dessas pessoas. Então a gente não tem nenhuma reclamação... Avaliamos como sendo um bom trabalho desempenhado por eles (P1).

O trabalho deles é muito satisfatório. A maioria deles tem muito compromisso com o trabalho, tem responsabilidade. Porque... assim, todo funcionário tem um serviço, e deixamos bem claro que daquilo que ele vai fazer nós esperamos responsabilidade, compromisso e vamos confiar no trabalho dele (P5).

Todavia, faz-se importante destacar que a maioria dos entrevistados apresenta uma concepção reducionista sobre trabalho, visto que se referem somente à capacidade produtiva dos sujeitos, enquanto, a partir do pressuposto adotado nessa pesquisa, o trabalho é entendido como categoria nuclear de análise como mediador das relações sociais humanas.

\section{Razões para contratação de PCD e critérios de admissão}

Embora apenas 30\% das empresas privadas pesquisadas na cidade de Bauru - SP cumpram a lei de cotas em seus números estipulados, todas elas (dez privadas e duas públicas) possuíam PCD em seu quadro de funcionários, e, a partir dos relatos dos entrevistados, observou-se que o principal motivo para contratação dessa demanda populacional está situado 
na obrigatoriedade da Lei no 8.213 . Assim, pode-se dizer que $100 \%$ dos entrevistados afirmaram que a contratação de PCD acontece primordialmente em obediência legal. Os relatos a seguir ilustram a subcategoria contratações em decorrência da lei de cotas.

Basicamente é a legislação. Se não tiver a obrigatoriedade da contratação, com certeza vão fazer a opção por contratar outras pessoas que não o deficiente [...] ele vai contratar porque é lei e é fiscalizado! (P4).

Olha, estaria sendo hipócrita se dissesse que não é pela lei de cotas. Porque a gente sabe que o que mais impulsiona a contratação de deficiente é a lei e ponto (P8).

Parece, então, que a lei de cotas cumpre o papel de viabilizar as contratações das PCD, uma vez que as empresas são obrigadas a criar vagas de trabalho para tal demanda populacional, que, até a implementação da lei, eram preteridas nos processos de seleção de mão de obra, fato este confirmado por alguns entrevistados.

Quando questionados sobre os pré-requisitos para admissão dos funcionários com deficiência, de acordo com os entrevistados, todo e qualquer candidato deve se enquadrar em alguns critérios para ser admitido pela empresa. Das 12 empresas participantes, 91,6\% revelaram que a exigência é a mesma, tanto para candidatos com deficiência como para candidatos sem deficiência alguma, exceto a necessidade de um laudo médico que comprove a condição de deficiente, para que assim possam enquadrá-lo em suas cotas exigidas pela lei. Compõem a subcategoria critérios para admissão de funcionários com deficiência.

O mínimo que nós pedimos, para cargos operacionais, no mínimo, o segundo grau completo [Ensino Médio completo]. E essa exigência é pra todo mundo, inclusive para os funcionários com deficiência (P2).

Segundo grau completo para qualquer funcionário. Agora, para as áreas técnicas, aí são profissionalizantes, entendeu? Aí tem que ser um eletricista, um cabeador, e precisam ter um curso específico. Mas, no geral, os pré-requisitos são os mesmos para todo mundo: digitação e segundo grau (P12).

De modo geral, o critério mais intensamente exigido pelas empresas é a escolaridade mínima (Ensino Fundamental completo), e ficou evidente que cabe ao candidato adequar-se às exigências estabelecidas pela empresa, e a responsabilidade pelo não cumprimento de tais critérios recai totalmente sobre o próprio indivíduo, pois não houve indícios da tentativa de adequação dos critérios nem dos postos de trabalho para os candidatos com deficiência. Com isso percebe-se quão importantes são as ações educacionais que promovam a escolaridade dos alunos com deficiência no ensino comum, desenvolvendo propostas de adequações curriculares para que o ensino comum possa atender essa demanda com qualidade educacional.

Embora haja a exigência da escolaridade mínima, os entrevistados não relataram haver dificuldades no recrutamento de PCD com a referida escolaridade, dado esse que diverge dos achados de Araújo e Schmidt (2006) e Tanaka e Manzini (2005).

O principal aspecto que dificulta a contratação e o posterior exercício do trabalho das PCD é com relação à estrutura física das empresas, ou seja, às barreiras arquitetônicas para locomoção das PCD dentro das dependências das empresas pesquisadas. Para os entrevistados, as barreiras arquitetônicas e a falta de adaptação do ambiente físico inviabilizam a contratação de determinados tipos de deficiências, tais como deficiência visual e deficiência física, principalmente no caso de cadeirantes, como já identificado por Araújo e Schmidt (2006). 


\section{Considerações Finais}

Embora os dados aqui apresentados não permitam generalizações, nota-se a desproporcionalidade entre o número total de empregados das empresas com e sem deficiência, indicando déficit em relação ao estipulado pela cota.

É inegável que o dispositivo legal que obriga as empresas a contratar sujeitos com deficiência abre a estes novos horizontes de vida, através do acesso ao trabalho. Contudo, de modo geral, a maioria das empresas, da amostra estudada, não cumpre a Lei de Cotas estabelecida pela legislação brasileira nem tampouco promove a ascensão profissional daqueles que estão contratados, ou seja, o cenário atual está distante das ideais condições de empregabilidade. Porém, parece ser um avanço quando se pensa que há duas décadas tal preocupação não era objeto de lei, estando muito longe da realidade empresarial brasileira.

Talvez, em virtude desses aspectos, percebe-se maior preocupação com relação ao âmbito jurídico da contratação de $\mathrm{PCD}$, em detrimento da própria inclusão social dessa demanda populacional. Dessa forma, foram identificadas poucas práticas que permitam classificar as empresas como sendo inclusivas. Carecem, pois, de adaptações arquitetônicas e administrativas para recebimento das PCD, de modo que a obrigação legal de contratação pode significar apenas uma inclusão formal.

As empresas ainda se mostram resistentes na contratação de PCD, visto o fato de selecionarem pelas deficiências menos "comprometedoras" ou aquelas que supostamente são favoráveis para as linhas de produção. Anache (1996) e Omote (1996) chamam a atenção para os prejuízos de se contratar PCD com base na deficiência e não nas reais competências e habilidades dos candidatos, ou ainda de se depositar uma expectativa irreal sobre o trabalho a ser desempenhado por tais profissionais. Anache (1996), referindo ao fenômeno discutido, diz:

Tal atitude é muito perigosa, causando prejuízos para ambos (empregador e empregado), porém com marcas mais profundas para a pessoa com deficiência que busca conquistar um espaço no mercado de trabalho, que nem sempre é compatível com suas reais potencialidades (p. 123).

Sobre as concepções dos entrevistados acerca das pessoas com deficiência, prevalece o modelo médico-jurídico ${ }^{4}$ sobre o fenômeno, respaldados pelos textos oficiais que trazem esse mesmo modelo. Assim, as leis e decretos que tratam de tal definição colocam equivocadamente a questão da normalidade, enquanto sugerem um "padrão normal" para o desempenho das atividades humanas. Nesse mesmo sentido, a Corde - Coordenadoria Nacional para Integração da Pessoa Portadora de Deficiência - define o sujeito com deficiência como aquele que tem "redução efetiva e acentuada da capacidade de integração social com necessidade de equipamentos" (Brasil, 1998)

Obviamente, dadas as condições de cada deficiência, não se pode negar a necessidade de equipamentos, a fim de ofertar aos indivíduos com deficiência condições equitativas. O que se contesta é a caracterização da deficiência como uma condição de incapacidade e anormalidade.

Nesta pesquisa, não se encontrou nenhum relato que se aproximasse da leitura da deficiência como um fenômeno social, já explicitado em parágrafos anteriores, modelo esse que não foca no sujeito as mazelas por sua condição. Ao contrário, mostra que os problemas das PCD estão muito mais focados na sociedade do que nelas mesmas, visto que, conforme Omote

4 Modelo adotado nas regulamentações normativas amparado no CID-10 (Classificação Estatística Internacional de Doenças e Problemas Relacionados à Saúde, OMS, 1997) que concebe a deficiência como uma perda ou anormalidade de uma parte do corpo (estrutura) ou função corporal (fisiológica), incluindo as funções mentais, cujo foco da condição de deficiente recai sobre o indivíduo. 
(2001), a audiência e a sociedade lhes cria problemas, atribuindo-lhes incapacidades e desvantagens.

Para a maioria dos entrevistados, as PCD ainda são aquelas que, a princípio, podem causar problemas no ambiente de trabalho. Constatou-se que as falas são impregnadas de elementos que localizam a deficiência no próprio sujeito, e não nas condições de trabalho proporcionadas, marcando-os como diferentes.

Embora a lógica do capital preconize a ideia de que são necessários cada vez mais novos trabalhadores e novos consumidores, a sociedade capitalista ainda não dispõe de meios eficazes para garantir a todos os indivíduos de uma sociedade a oportunidade de inclusão no mundo do trabalho. Isso parece contraditório, pois na esfera nacional, ao se pensar em marcos históricos na área empregatícia, tem-se o Decreto no 3.298/99, que regulamenta o emprego e a inserção da pessoa com deficiência ao mercado de trabalho, bem como a sua incorporação ao sistema produtivo mediante regime especial de trabalho protegido (oficina abrigada), buscando implementar ações que garantam o direito de participação social das PCD em todas as instâncias, legitimando leis normativas na luta por uma sociedade menos desigual.

Entretanto, deve-se destacar o papel fundamental das empresas - públicas ou privadas - no processo de empregabilidade das PCD. Para o Instituto Ethos (2002), as empresas têm o compromisso ético de promover a diversidade dentro de suas próprias instalações e ainda lutar pela redução das desigualdades sociais. Os empregadores precisam romper as barreiras dos mitos e reconhecer as potencialidades das PCD, empregando-as e dando-lhes condições de desenvolvimento profissional e pessoal, ou seja, atuando como propulsores do desenvolvimento humano, condição essa não identificada no estudo.

Acredita-se que a solução da maioria dos problemas enfrentados, quando da inclusão social das PCD no mercado de trabalho, deve passar por mudanças além das políticas públicas, ou seja, atingir a sociedade em geral, por intermédio, talvez, da veiculação maciça da capacidade laboral dessas pessoas e do resgate da sua condição de cidadão, para que não sejam julgados como indivíduos de segunda ordem. Isso parece ainda ser um grande desafio para a sociedade atual. Ao Estado cabe o papel de financiador, regulador e fiscalizador. À sociedade cabe o papel de participar ativamente no processo de debate de ideias, exigindo a inclusão social de todas as demandas populacionais marginalizadas.

Por fim, por intermédio desta pesquisa, pode-se constatar que a Lei de Cotas apenas cumpre o papel de viabilizar a empregabilidade das PCD, sem, entretanto, garantir a real inclusão social de tais pessoas. Destarte, não bastam leis e decretos, é preciso que tudo isso seja efetivamente implementado por meio da participação ativa da sociedade que deverá entender a pessoa com deficiência como um indivíduo capaz de se desenvolver como ser humano e se tornar sujeito responsável por sua história, uma vez que lhes sejam dadas as condições necessárias.

\section{Referências}

Amaral, L. A. (1992). Espelho convexo: o corpo desviante no imaginário coletivo, pela voz da literatura infanto-juvenil. Tese de Doutorado, Instituto de Psicologia, Universidade de São Paulo, São Paulo.

Amaral, L. A. (1992). Mercado de trabalho e deficiência. São Paulo: Senai.

Amaral, L. A. (1998). Sobre crocodilos e avestruzes: falando de diferenças físicas, preconceitos e sua superação. In J. G. Aquino (Org.), Diferenças e preconceitos na escola: alternativas teóricas e práticas (pp. 11-30). São Paulo: Summus.

Amiralian, M. L. T. et al. (2000). Conceituando deficiência. Revista de Saúde Pública, 34 (1), 97-103. 
Anache, A. A. (1996). O deficiente e o mercado de trabalho: concessão ou conquista? Revista Brasiliera de Educação Especial, 2 (4), 119-126.

Aranha, M. S. F. (2003). Trabalho e emprego: instrumento de construção da identidade pessoal e social. Brasília: Corde.

Araújo, J. P. \& Schmidt, A. (2006). A inclusão de pessoas com necessidades especiais no trabalho: a visão de empresas e de instituições educacionais especiais na cidade de Curitiba. Revista Brasileira de Educação Especial, 12 (2), 241-254.

Bahia, M. S. (2006). Responsabilidade social e diversidade nas organizações: contratando PCD. Rio de Janeiro: Qualitymark.

Brasil. (1988). Constituição da República Federativa do Brasil.

Brasil. (1999). Decreto no 3.298 de 20 de dezembro de 1999.

Dejours, C. (1999). A loucura do trabalho: estudo de psicopatologia do trabalho (3ª ed.) São Paulo: Cortez.

Figueiró, R. F. S. (2007). O paraplégico no mercado de trabalho - a percepção dos trabalhadores sem deficiência motora: contribuições da enfermagem para a equipe multidisciplinar. Tese de Doutorado, Escola de Enfermagem Anna Nery, Universidade Federal do Rio de Janeiro, Rio de Janeiro.

Goffman, E. (1998). Estigma: notas sobre a manipulação da identidade deteriorada (4ª ed). Rio de Janeiro: LTC.

Ethos, Instituto Ethos de Empresas e Responsabilidade Social. (2002). O que as empresas podem fazer pela inclusão das PCD. São Paulo: Instituto Ethos.

Lima, M. (2007). Como empregar sem discriminar. Ciência e Profissão: Diálogos, 4 (5), 19-21.

Marx, K. (1993). Manuscritos econômicos-filosóficos. Lisboa: Edições 70.

Miranda, T. G. (2006). Trabalho e deficiência: velhos desafios novos caminhos. E. J. In Manzini (Org.), Inclusão e acessibilidade (pp. 159-170). Marília: ABPEE.

Neri, M. (2003). As empresas e as cotas para PCD. Conjuntura Econômica: Temas Sociais.

Omote, S. (1987). Estereótipos a respeito de pessoas deficientes. Didática, 22 (23), 167-180.

Omote, S. (1996). Perspectivas para conceituação de deficiências. Revista Brasileira de Educação Especial, 2 (4), 127 135.

Omote, S. (1999). Deficiência: da diferença ao desvio. In E. J. Manzini \& P. R. Brancatti (Orgs.), Educação especial e estigma: corporeidade, sexualidade e expressão artística (pp. 3-21). Marília: UNESP/CAPES.

Omote, S. (2001). A concepção de deficiência e a formação do profissional em educação especial. In M. C. Marquezini, M. A. Almeida \& E. D. O. Tanaka (Orgs.), Perspectivas multidisciplinares em educação especial II (pp. 45-52). Londrina: UEL.

Napolitano, C. J. (2003). A liberdade de iniciativa e os empreendedores econômicos estrangeiros na Constituição Federal: uma análise do direito fundamental à propriedade à luz das Emendas Constitucionais. Dissertação de Mestrado, Instituição Toledo de Ensino de Bauru, Bauru.

Pastore, J. (2002, 29 de maio). As cotas incluem e excluem. Jornal da Tarde, São Paulo.

Sassaki, R. K. (1997). Inclusão: construindo uma sociedade para todos. Rio de Janeiro: WVA.

Silva, G. P. (2007). O significado do trabalho para o deficiente visual. Dissertação de Mestrado, Programa de PósGraduação em Psicologia, Pontifícia Universidade Católica de Minas Gerais, Belo Horizonte.

Tanaka, E. D. O. \& Manzini, E. J. (2005). O que os empregadores pensam sobre o trabalho da pessoa com deficiência? Revista Brasileira de Educação Especial, 11 (2), 273-294.

Teixeira, R. C. F. (2003). A passagem do "direito ao trabalho" para a "empregabilidade": privatização do espaço público através das políticas sociais de emprego na contemporaneidade. Unimontes Científica, Montes Claros, 5 (1).

\section{Endereço para correspondência}

rr.violante@yahoo.com.br, lucialeite@fc.unesp.br

Recebido em: 26/01/2010

Revisado em: 15/06/2010

Aprovado em: 15/07/2010 